\title{
Building Socio-Moral Behaviour in Romanian Middle-School Education
}

\author{
Lupu Costică ${ }^{1 *}$
}

\section{ABSTRACT}

Moral and civic education is complex and achieved in time. Students are active subjects of society involved in community life by means of their families, groups of friends but also specific relationships they have with various institutions. Moral development theories are elements that support the illustration and translation of the educational space into the form of skills, moral habits, positive character traits expressed at the level of the school population. Our research demonstrates the importance of using moral and civic education strategies consistent with the curriculum objectives and content, to contribute to the formation of character traits and sociomoral behaviour of students. The theme was researched during the 2015-2016 school year at "G. M. Cancicov" Middle School Bacău and involved the support of 4 headmasters of 6th-grade classes, together with 2 teachers of Civic Culture and Religion teaching at these classes. The research group consisted of 90 students, aged 12-13, of whom 45 are girls and 45 boys. There were applied initial evaluation, formative evaluation and final evaluation tests. Comparing the results from the initial and final evaluations it was found that the students' situation has improved, most students have translated into practice the theoretical elements accumulated, they built a sense of will and character, as well as moral feelings (friendship, comradeship, respect, etc). From the observations made in various situations it was found that all students have acquired certain moral norms, theoretical aspects were put into practice to a higher degree, students showed more respect towards older, vulnerable people and others, became more polite, with attitudes of openness towards others, regarding punctuality, sincerity and other features as compulsory character traits.

Keywords: Applied Research, Moral-Civic Education, Moral Development Theories, Educational Process

Moral-civic education emphasizes interdisciplinary activities. The teacher's task is to shape and

\footnotetext{
1 “Vasile Alecsandri” University of Bacău, 157 Mărăşeşti Street, Bacău, Pre- and In-Service Teacher Training Department, România

*Responding Author

(c) 2016, C Lupu; licensee IJIP. This is an Open Access Research distributed under the terms of the Creative Commons Attribution License (http://creativecommons.org/licenses/by/2.0), which permits unrestricted use, distribution, and reproduction in any Medium, provided the original work is properly cited.
} 


\section{Building Socio-Moral Behaviour in Romanian Middle-School Education}

model the character of children so that the basis of the personality of the future young person may be a solid one, free from the influence of negative situations that may inherently arise.

The paper presents some aspects from the theories of J. Piaget, L. Kohlberg, E. Erikson, Allport and Carol Gilligan on the stages and levels of moral-civic behaviour development and the objectives of moral education (the formation of moral conscience and moral behaviour).

Because the essence of morality is the respect granted by the individual to rules, there are presented the main strategies of moral education. Achieving moral education requires choosing the most effective methods and procedures that form and develop the socio-moral behaviour of students.

The presentation of the methodological coordinates of the applied research and interpretation of results obtained in the evaluation tests highlight the teacher's role in creating the incentive for mastering and applying the rules of moral conduct.

\section{THEORIES ON THE DEVELOPMENT OF MORAL BEHAVIOUR}

\section{J. Piaget's theory}

J. Piaget's research substantiates the concept of human behaviour development, of what he calls the morality of constraint, under which the child receives from the adult a number of rules that he must obey under any circumstances and the morality of cooperation, implying the autonomy of conscience, the intentionality of moral acts, individual responsibility.

Every rule (norm), as J. Piaget highlighted, starts as external to consciousness before undergoing internalization; it is translated into practice when it corresponds to an internal need, to the extent in which the habit of cooperation will convince the child of its necessity, namely not to lie, to be fair, disciplined, respectful etc.

J. Piaget (1980, p. 210) points out the stages of moral development: The stage of motricity (and of the motor rule), the rules exercised favour the gradual formation of moral regularity; The second stage is that of egocentric behaviour, of imitating the moral rule imposed from the outside. At this stage, the child is not concerned with the codification of moral rules, but his individual behaviour develops parallel to the constraint exercised by the adult, the moral rule being considered sacred; The stage of cooperation or compliance with common rules. It is a stage corresponding to the age of 7-10, when compliance with moral rules is a behaviour obligation. Characteristic of this stage is the fact that respect is reciprocal (mutual). Therefore, moral rules and norms will be internalized and become internal motives of conduct as a natural consequence of a process of coordination where both poles are involved.

(c) The International Journal of Indian Psychology, ISSN 2348-5396 (e)| ISSN: 2349-3429 (p) | 156 


\section{Building Socio-Moral Behaviour in Romanian Middle-School Education}

The stage of moral autonomy, of decoding moral values and norms through the emergence of interest in them, at the age of 11-12-14, and of reuniting the rules of moral behaviour into a moral law. Autonomy is not possible outside of cooperation, of mutual relationships that facilitate the internalization of external moral commands on the internal individual behaviour.

\section{Kohlberg's view}

In L. Kohlberg's view, moral education is achieved throughout human life, moral development being marked by periods of intense transformations. This statement relies on three findings: - at birth, man is devoid of any moral endowment; - moral development is a sequential process, being a consequence of the development of human intellect; - social interaction is the source of moral development and education, stimulating the restructuring of the child's own life experiences.

Kohlberg places at the forefront, based on his view upon man's way of relating to society, the values of right and justice (righteousness) as defining of the child's moral behaviour development. Also, he correlates the concept of stability with the level of moral development understood as its graduality or height. In his view, moral development covers a preconventional, a conventional and a post-conventional level, each of these levels comprising two developmental stages. The maturing of moral judgment covers six stages. The stages indicate three levels of judgment, qualitatively different from each other.

Level I. Pre-conventional morality, specific to until 10 years of age. The judgment standards: "good / bad”; "nice / naughty"; actions are judged by their consequences.

Stage I - the morality of obedience and submission. At this stage, the child analyses the positive or negative consequences of an action and most often obeys rules to gain immediate personal advantages. Stage II - the morality of naively instrumental hedonism. Obedience to the rule stimulates the child because it is a source of benefits. Therefore, a good deed must appear as being to his own advantage and less to the benefit of others.

\section{Level II. Conventional morality (age 10-13)}

Facts are judged by reference to the system of rules and compliance is derived from the pleasure of being granted the status of "good behaviour", the requirement of the reference group, the family, group of friends, school, etc. being highly relevant.

Stage III - the moral behaviour of the good child, seeking to have good relations with others in order to be appreciated and accepted. The child feels the need to be in compliance with the norms of the group to which he belongs and regards himself as being good when adopting the behaviour that pleases others.

Stage IV - of maintaining the authority (of the social system). Respect for authority, for the rules governing the conduct of all, which also acts for personal gain. 
Level III. Post-conventional morality (the moral of self-acceptance principles (after the age of 13).

Relating to the norm is the basic criterion in the analysis of moral acts. There takes shape one's own moral system. Stage $V$ - of individual rights and social contract. Laws and rules are not intangible, they can be changed by mutual agreement, aiming at their general usefulness. Stage $V I$ - of the universal principles of self-consciousness. It is the stage of universal moral values (justice, equality, respect for individual dignity). The judgment itself is perceived as stronger than the one that comes from the outside. According to Kohlberg's view, moral education is required throughout life as a result of the changes and transformations undergone by man, changes entailing new life demands.

\section{E. Erikson's theory}

According to Erikson's theory, the individual's development potential achieves fulfilment throughout life, with new acquisitions occurring at each stage of life. They are caused by the presence of developmental crises, periods with special formative resources. These are based on complex individual potentialities and those of the socio-cultural environment. In their concrete form, they appear as genuine challenges: Can I be autonomous? Do I know who I am?, Am I capable of personal expression in various aspects of life? etc. Depending on the quality of social support, but also the adaptive capacities of the individual, psychosocial development is focused, at every stage, on an optimal direction or a less happy alternative, through basic acquisitions: trust / distrust, competence / inferiority etc. Since each of these acquisitions offers the person a new truth about himself, a new psychological dimension, the stages proposed by Erikson are considered distinct phases. (Călin, Marin, 2003, p.67).

The stability of development in Erik Erikson's view

\begin{tabular}{|l|l|l|l|}
\hline $\begin{array}{l}\text { Chronological } \\
\text { benchmarks }\end{array}$ & Basic polar acquisitions & $\begin{array}{l}\text { Determining social } \\
\text { factors }\end{array}$ & Identity dilemma \\
\hline $0-1$ & Trust / mistrust & Maternal care & Am I safe? \\
\hline $2-3$ & Autonomy/ doubt and shame & Parents & Can I do this by myself? \\
\hline $4-5$ & Initiative/ guilt & Wider family circle & Do I have a choice? \\
\hline $13-18$ & Industry /inferiority & School and family & $\begin{array}{l}\text { Am I doing as well as the } \\
\text { others? }\end{array}$ \\
\hline Young age & Identity /confusion & $\begin{array}{l}\text { Models and similar- } \\
\text { age groups }\end{array}$ & Who am I? \\
\hline Adult age & $\begin{array}{l}\text { Generativity / stagnation (the } \\
\text { power to generate) }\end{array}$ & $\begin{array}{l}\text { Family and profession } \\
\text { relationships }\end{array}$ & $\begin{array}{l}\text { Do I have the force and } \\
\text { responsibility of creative } \\
\text { expression? }\end{array}$ \\
\hline Old age & Integrity /despair & $\begin{array}{l}\text { Approaching } \\
\text { retirement and the end } \\
\text { of one's life }\end{array}$ & $\begin{array}{l}\text { Are my achievements the } \\
\text { expression of my true self? }\end{array}$ \\
\hline
\end{tabular}

(C) The International Journal of Indian Psychology, ISSN 2348-5396 (e)| ISSN: 2349-3429 (p) | 158 


\section{Building Socio-Moral Behaviour in Romanian Middle-School Education}

\section{G.W. Allport's view}

G.W. Allport approached the stability of moral behaviour development from the perspective of the difference between authoritative moral conscience, external to one's childhood and the moral conscience characteristic of the adolescent. The former is a consciousness that says must and lies under the sign of it is compulsory, it is a developing consciousness through which the child learns obedience based on parental restrictions and prohibitions. The second moral conscience is defined as should, it has a structure that is not supported by the fear of punishment, but becomes a kind of generic self-orientation arising from a sense of duty and the capacity to rationally recognize the consequences of failure to comply with the moral values and norms in society. According to this view, moral development works on two structural components: character and culture.

The character is a neuro-psychic adaptive and expressive behaviour structure that designates its individual and specific features. Character traits are not fixed, they are subject to change due to cultural differences in society (e.g. sincerity or honesty can become major traits in a given situation).

Culture is decisive in the evolution of the functionality of the child's self, due to a "network of role relations" established by the social system. According to G. W. Allport (1981, p.143), the stadiality of moral behaviour development and training covers the following stages: - the initial stage, the first three years of life; - the second stage, from 4-6 years; - the third stage - from 6-12 years; - the fourth stage - adolescence.

\section{Carol Gilligan's approach}

The author conducted a series of studies on Kohlberg's model and concluded that his theory reflects, to a greater extent, masculine thought, but in reality boys / men and girls / women adopt different perspectives regarding moral issues.

According to Gilligan, boys are taught to be independent, focus more on competition, justice and fairness whereas girls are oriented to provide care and focus more on the needs of others. Based on this conclusion, it results that women go through different moral stages and levels than men, Carol Gilligan proposing a structure of women's moral development (Miroiu, M, 2002, p.125).

The first level - the focus on individual survival. At this level, there is a conflict between their own desires and the choice between doing something for oneself and doing what needs to be done which makes the shift from selfishness to responsibility.

The second level - goodness as self-sacrifice. At this level, there is a shift from kindness to truth and the desire to be responsible towards others.

The third level - called the morality of nonviolence. The basis of all moral judgments is the principle of nonviolence. It takes into account human well-being as universal obligation that allows women to recognize a moral equality between themselves and others. The author contradicts Kohlberg who considers that girls generally stop in their moral evolution in the third stage, namely the stage of interpersonal consistency and concludes that the third level of 


\section{Building Socio-Moral Behaviour in Romanian Middle-School Education}

feminine moral thinking is as abstract and post-conventional as the highest stages from Kohlberg's model.

Drawing a comparison between the theory of Kohlberg and that of Gilligan we may notice that the former focuses on an ethic of rights based on a formal logic of correctness and the other on an ethic of care based on a psychological logic of relationships.

\section{THE OBJECTIVES OF MORAL EDUCATION}

\section{The formation of moral conscience}

The moral conscience - reflects the way of relating to one's own rules, principles, moral habits and actions as well as those of others. The moral way of acting and thinking is related to the dimension of consciousness. At the level of moral conscience there is achieved the project of the moral act that is completed by approval or disapproval.

By the cognitive component, the child assimilates concepts, ideas. The exigencies of moral values, norms and rules are reflected in the formation of moral representations, judgments and reasoning. It is achieved through moral instruction, which begins in the family but is continued systematically and consistently through education.

The affective component is aimed at training the emotions of the moral feelings that represent the energetic substrate needed to transform knowledge into moral conduct.

The cognitive and affective component should merge with the volitional one (voluntary effort) to generate moral convictions, considered to be the core of moral conscience, true spiritual necessities of moral behaviour (Dumitriu, C., 2007, p.115).

Moral representation is a reflection in the form of an intuitive picture of the various elements characteristic of a complex of situations and concrete moral actions in which the child has been involved or that he has perceived, observed in relation to the same moral rule.

By generalization and abstraction there is achieved the moral notion. It reflects what is essential and general for a class of moral manifestations that a moral norm or rule encompasses, the appreciative nature expressing itself through moral judgment.

Merging the three components - cognitive, emotional and volitional - generates moral beliefs. They are regarded as the nucleus of the moral conscience of the individual, true spiritual necessities of moral behaviour. The unity of these components within a belief may be expressed as follows: the child knows and understands the moral norm, feels the need and exhibits adhesion to it, acting in accordance with the requirements that it prescribes.

Moral conduct is interpreted as an objective belief in moral facts and actions (Nicola, Ioan, 2003, p. 253- 257).

\section{The formation of moral behaviour}

Moral conduct includes the set of activities consciously developed, the set of all mental activities and the set of decision-making acts. Summarizing, moral conduct is nothing but an objectification of moral conscience into deeds and actions. From the psychopedagogical 


\section{Building Socio-Moral Behaviour in Romanian Middle-School Education}

perspective, behaviour education aims at building skills and habits of moral behaviour as well as positive character traits.

Moral habits are automated activity components that have moral content and meaning. We learn to be polite in all circumstances, help others, reject lies, complete the actions started.

Habits - imply the need to act in a certain way (the habit of congratulating someone, of being amiable, the habit of being late, of not keeping one's promise etc.)

When the act is triggered not only because of external circumstances, but also due to an internal need, the skill has turned into habit. Most skills and habits express certain relationships between people. They are formed amid stereotypical circumstances ensuring the necessary conditions for practicing and automating them.

Moral conduct is a series of manifestations and answers. Their automation in the form of skills and habits facilitates less control from consciousness, since automatisms enter its peripheral areas, thus providing the individual with the ability to focus his forces on achieving other duties. The child crystallizes elements of moral behaviour when offered real-life models patterns and aesthetic arguments from stories: it is nice to be polite, to listen to older people, to play with other children, etc.

In formulating skills and habits of moral behaviour the teacher takes into account the individual particularities of students. The differences between them are manifested along the line of their ability to understand moral requirements, assess moral acts, along the line of their will power and the quality of their character, of the experience gained up to that moment etc.

Character traits, like skills and habits, are also formed through activity. In terms of content, we distinguish between traits that express the human attitude towards society and, implicitly, his fellow men, towards work and himself.

The first category includes: cooperative spirit, love for one's country, uprightness, sociability, honesty, humanism, optimism, etc.

The second category includes: industriousness, initiative, mutual-help spirit, punctuality etc.

The last category includes: modesty, dignity, critical spirit, courage etc. (Nicola, Ioan, 2003, p. 257-261).

Positive character traits are formed in the process of human interaction with the social environment, an interaction that is objectively manifested, man being drawn into a complex web of social relationships, as a member of various communities (family, school, work) where he expresses, in one way or another, his attitude. The educational actions organized by the teacher are mostly aimed at building positive traits, and preventing and eliminating negative ones, when he finds that his students are faced with alternatives or display certain weaknesses in their behaviour.

\section{The content of moral education}

Moral education content reflects two coordinates, aimed at relating man to society (moral-civic education) and to oneself (moral-individual education). (C. Dumitriu, 2007, p.95). 


\section{Building Socio-Moral Behaviour in Romanian Middle-School Education}

Moral-civic education has a predominantly social character expressed in particular at the level of: education policy (democratic, humanist, patriotic), economic education (education through and for work), legal education (education by and for the community). Moral-individual education has a determining content aimed at relating man to oneself, being expressed at the level of philosophical education, religious education, materializing in the form of acquisitions of “personal virtues": honesty, sincerity, courage, fairness and social: moral-civic attitudes.

The religious perception of the world positions, by itself, man and humanity on the path to moral rectitude (Cucoș C., 2000, p.160).

In the current social situation, moral education content has a pronounced civic character, reflecting the values of open competition, generalized at the economic (market economy), political (participative democracy) and cultural (computerization applied in all areas) level.

Moral education implies the idea of "complexity” as the moral phenomenon itself involves moral necessities and moral relations, individual, or group, as these belong to the structure of the moral phenomenon, plus the constituent levels of human behaviour.

Moral exercise, the exploitation of concrete life situations in the classroom or group, the real offer of choices to support the effort in action to overcome obstacles are some of the ways that educators can use to create self-control mechanisms and build will. (Jeder, Daniela, 2006, p 205).

\section{APPROACHING MORAL - CIVIC EDUCATION IN SCHOOL}

The educational process is the basic way in which the primary objective of moral education is achieved. Through the educational content of the various school disciplines the moral training of children is achieved. There is no activity whose content cannot be exploited to build moral conscience and moral conduct.

School, as part of society, together with family, church, without ignoring the lasting, traditional values of the native and universal culture, infuses, cultivates and develops the creative side of youth with a view to their artistic, moral, scientific and social development.

Moral-civic education meets the need to build at students a behaviour that relies on everyday knowledge of the rules of social life in a democratic state.

Moral-civic education aims to initiate the child, the future citizen, into the practice of active, responsible behaviour, capable of showing tolerance and respect for oneself and others, aware of his rights and duties, free and open to other cultures.

Possible topics to be addressed are: The person; Moral traits of the person; We and things; We and other creatures; We and groups; Our relationships with other people; Relations between people in different situations; Child rights; The Community; Society and the state;

These themes can be approached through: - moral explanation by means of moral incentive- and information-based processes that can be retrieved from other methods; - moral lecture based on a volume of information provided through verbal-expository processes such as pleademonstration; - moral conversation, based on moral dialogue procedures, moral debate, moral

(C) The International Journal of Indian Psychology, ISSN 2348-5396 (e)| ISSN: 2349-3429 (p) | 162 


\section{Building Socio-Moral Behaviour in Romanian Middle-School Education}

story, moral comment; - moral example, with methods based on direct-indirect, real-imaginary examples; - case analysis based on decision-making processes, presentation, analysis, discussion, moral recommendation; - moral exercise; - moral approval based on processes and techniques of praise, gratitude, reward; - moral disapproval based on processes and techniques of observation, irony, punishment, etc;

In this respect, the themes of moral-civic education will help children: - to know and respect the rules of moral behaviour in society and the rules of personal conduct; - to adapt behaviour to the requirements of the group in which one lives (family, school, play group); - to assess, specific situations, certain behaviours and attitudes in relation to predetermined and known rules; - to experience, in relationships with others, positive emotional states, to show friendship, tolerance, harmony, along with learning self-control;

At the level of the curricular area Man and Society, students learn about behaviour patterns in the spirit of moral values that were imposed in society over time. Thus, historical legends reveal to the child the models of social organization from ancient to the modern and contemporary times. Knowledge of the historical premises for building and asserting the virtues of the people to which children belong generate feelings of appreciation for the courage and bravery of their ancestors. Building on these true examples of heroism, the student acquires positive life patterns, showing attachment to historical and national values (Bunescu, V, 1991, p. 56).

\section{METHODOLOGICAL COORDINATES OF THE APPLICATIVE RESEARCH}

\section{Research hypothesis}

Based on the scientific and pedagogical arguments presented in the first two chapters, we propose a practical approach to the subject matter of our research.

If we use moral-civic education strategies consistent with the syllabus objectives and contents, we shall contribute to building character traits and socio-moral behaviour at students.

\section{Research objectives:}

1. Identification of the initial level of socio-moral development of students in primary education;

2. Design and conduct of educational activities with moral and civic content;

3. Optimal exploitation of the most formative and educational valences of these activities;

4. Identification of the progress of students during and after the practical approach.

\section{Research group and stages}

The theme was researched during the 2015-2016 school year at "G. M. Cancicov” Middle School Bacău and involved the support of 4 head masters of $6^{\text {th }}$-grade classes, together with 2 teachers of Civic Culture and Religion teaching at these classes. The research group consists of 90 students, aged 12-13, of whom 45 are girls and 45 boys. There were applied initial evaluation, formative evaluation and final evaluation tests. 


\section{Building Socio-Moral Behaviour in Romanian Middle-School Education}

Since the relationship behaviour is most eloquent in child development, it was ensured that observation related to: - child relationships with work and play; - child relationships with surrounding objects; - student relationships with others (parents, children); - student relationships with himself.

In terms of motor skills, the students are physically well developed and have psycho-motor coordination appropriate to their age.

At the intellectual level, our research was aimed at finding the degree of knowledge in terms of "what the student knows" and how he uses "what he knows in everyday life", but also how he solves various problems (curiosity, learning method, verbal and non-verbal language, classification methods, estimation etc.).

Of the 90 students, 80 students are receptive to any information, show curiosity, good memory, are able to solve problems with or without intuitive material, use appropriate language. Ten of them come from broken and disinterested families, have limited vocabulary, with an impact upon building interpersonal relationships, hindering communication and collaboration with other students, hence also difficulties in following certain rules. By engaging them in activities, they have begun to gain confidence in what they do and understood that rules must be obeyed, the best proof for this being their actions. During this period, there were observed both positive and negative student behaviours. Improvement measures were created for implementation in the following stages by designing activities with moral content.

A single-sample "before-and-after" research technique was chosen because the results obtained at the tests are more conclusive and provide objective information on the socio-moral behaviour development of students.

The research comprised three stages:

1) the stage of initial evaluation, covering the interval between October $10^{\text {th }}$ to November $10^{\text {th }}$ 2015, focused on the teacher's acquiring knowledge about the students from the perspective of the established objectives. To this end, there was conducted an initial evaluation to assess the students' level of socio-moral behaviour development. The used methods were observation, free and guided conversation, test (worksheets).

2) the ameliorative stage was conducted by designing and carrying out a methodical approach centred on developing character traits and socio-moral behaviour at $6^{\text {th }}$ graders. At this stage, there were covered the themes: The people around me; Persons with special needs; A plea for respect; Goodness and malice, Life in stripes; The play group; Family; Our attitude towards plants and animals, etc. At the end of this stage, students were applied formative assessment to record their progress or regress in forming a socio-moral behaviour. 


\section{Building Socio-Moral Behaviour in Romanian Middle-School Education}

3) the final evaluation stage, April 15 to April 30, 2016, consisted of permanent observations, culminating in a final evaluation test to determine the students' level of socio-moral behaviour and how they have evolved from initial testing.

\section{Research methods used}

Observation consisted in intentional, systematic and accurate monitoring and recording, by the head teachers of the investigated classes, the various behavioural manifestations of students as these naturally occurred.

Conversation was conducted according to a plan and clearly formulated questions, appropriate to the situation and related to concrete aspects. The aim was to know how students relate in school, during breaks, how they receive the influences of the educational family and institutional environment.

The evaluation tests elaborated by the teacher of Civic Culture were mainly aimed at identifying the level of knowledge, along with the introduction of the progress factor, materialized as the gradual structuring of knowledge from simple to complex.

The case study consisted in analysing specific cases of real life to synthesize knowledge, and develop the students' ability to find solutions to problem situations.

The analysis of activity products consisted in analysing various products of the students' work and school documents in order to reveal personality traits of students by objectifying them in work products, written assignments, individual worksheets, artistic activities, extracurricular activities.

The role play consisted in improvising a play and a historical story by students' acting the main roles. At the end, there was conducted a debate of the situations created involving all the students in the class, to emphasize the educational aspects.

\section{Presentation, analysis and interpretation of the results obtained in the initial evaluation}

Objectives: - to recognize the moral traits of a person; - to differentiate positive from negative traits; - to identify the proverb to which the task refers; - to explain the meaning of the proverb. The results of the initial evaluation showed that out of 90 students, only 30 students (33\%) obtained the mark VW (very well), having identified the moral traits of a person and provided the necessary explanations of the proverb. Another 40 students (45\%) failed to address the test requirements and offer a full explanation of the proverb, which means that they cannot recognize the moral traits of a person.

Unsatisfactory results were obtained by 20 students (22\%), who failed to correctly identify the terms that referred to the moral traits of a person and provided no explanation of the proverb. Therefore, to assist to their needs, we organized various activities for the students to acquire the necessary concepts and translate them into moral behaviours. 


\section{Building Socio-Moral Behaviour in Romanian Middle-School Education}

Presentation, analysis and interpretation of the results obtained in the formative evaluation This stage was the longest, covering a range of topics of moral and civic education. To reach the objectives, it is necessary to conduct a series of activities, games, stories in the school library, visits to various institutions and other types of activities designed to raise the child's awareness. The new knowledge assimilated by the student will complete the formation of skills and abilities that will enable the child to adapt to all requirements and rules that society imposes.

Civic Culture aims to initiate students to the practice of civic behaviour in a democratic society, an active, free, responsible, open and communicative behaviour. It offers the opportunity to use age-specific experience by emphasizing the emotional attitudinal dimensions associated with the cognitive one, stimulating participation and responsible social communication. There were developed and established the following frame objectives:

\section{Knowledge of and compliance with social behaviour rules}

Reference objectives: - to respect and use social behaviour norms and rules; - to adapt behaviour to the situation created.

Examples of behaviours: - accept and respect group coexistence rules; - show care and tolerance towards people with special needs; - express civic opinion in a given situation.

\section{Educating the positive traits of will, character and developing a positive attitude towards} oneself and towards others

Reference objectives: - to appreciate, in concrete situations, behaviours and attitudes in relation to predetermined and known rules; - to show attitudes of friendship, harmony, respect towards others.

Examples of behaviours: - to evaluate their own behaviour in relation to the rules of social living; - to realize the positive and negative consequences of their behavioural acts upon themselves and others; - to adapt their behaviour to different situations.

\section{Development of relational behaviour related for the establishment of social groups}

Reference objectives: - to describe and compare the types of relationships and social attitudes (cooperation, competition, solidarity, tolerance, intolerance) from the given situation.

Examples of behaviours: - to accept the diversity of opinions and attitudes; - to use social behaviour rules.

At the end of the formative period, the students filled in a test on the identification of the moral traits of a person by evaluating the following objectives: - associate words according to their quality / defect meaning; - differentiate positive from negative moral qualities; - identify the moral trait corresponding to the picture; - build sentences using the words given.

Analysing the results from the formative assessment we found that 45 students (50\%) were able to identify the moral traits of a person as required by the test and obtained the grade Very Well, 


\section{Building Socio-Moral Behaviour in Romanian Middle-School Education}

35 students (39\%) obtained the mark Well as a result of their mistaking of terms. We also found that of the 20 students who had obtained Sufficient in the initial evaluation, only 10 students (11\%) have obtained this qualification in the formative assessment, the other 10 having succeeded in obtaining the mark Well, which means that they have identified several moral traits and accumulated new knowledge.

\section{Presentation, analysis and interpretation of results obtained in the final evaluation}

The final evaluation stage consisted of permanent observations of students during breaks, at the theatre, during various school activities and during the Easter visit at the Caritas Shelter. This stage concluded with a final evaluation test to determine the level of moral-civic behaviour. We further present the objectives of the final evaluation, the test items and performance descriptors.

Objectives: - to differentiate positive from negative traits in a given context; - to discover the moral trait highlighted by some proverbs; - to show kindness, honesty, respect towards peers; - to translate into action the formation of moral skills accessible to their age.

\section{Items:}

1. Unite the words in the two columns depending on their connection (their meaning, whether they refer to a quality or flaw)

\begin{tabular}{|c|c|}
\hline Truth & Respect \\
\hline Lie & Lack of respect \\
\hline Politeness & Sincerity \\
\hline Common-sense & Courage \\
\hline Trust & Cowardice \\
\hline Unjustified praise & Honesty \\
\hline
\end{tabular}

2. Discover the moral trait emphasized by the given proverbs:

a) "Hello Hat, since the owner has no mouth!"

b) "A tree with strong roots is not afraid of the storm."

c) "Kind words are like honey."

d) "Doing good will be repaid with good."

3. Specify characters according to the qualities that characterize them:

\begin{tabular}{|l|l|l|l|l|}
\hline Kindness & Malice & Courage & Lie & Sincerity \\
\hline & & & & \\
\hline
\end{tabular}

4. Answer by YES or NO:

a) You should trust all people, even those you see for the first time. ( )

b) He who does not respect others, does not respect himself. ( )

c) Ioana is the best colleague, because she lets us copy from her notebook. ( )

d) Good deeds are done without any interest; helping others makes you feel good. ( )

5. Make a suggestive drawing to illustrate the proverb: "Don't do unto others what you don't want others to do unto you!" 
Building Socio-Moral Behaviour in Romanian Middle-School Education

Performance Descriptors:

\begin{tabular}{|l|l|l|l|}
\hline \multicolumn{1}{|c|}{$\begin{array}{c}\text { Item } \\
\text { number }\end{array}$} & \multicolumn{1}{|c|}{ Very well } & \multicolumn{1}{c|}{ Well } & \multicolumn{1}{c|}{ Sufficient } \\
\hline $\mathbf{I}_{\mathbf{1}}$ & $\begin{array}{l}\text { Unite the words in the } \\
\text { two columns according } \\
\text { to their quality/defect } \\
\text { connection; }\end{array}$ & $\begin{array}{l}\text { Unite the words in the two } \\
\text { columns with a mistake; }\end{array}$ & $\begin{array}{l}\text { Unite the words in the two } \\
\text { columns with two mistakes; }\end{array}$ \\
\hline $\mathbf{I}_{\mathbf{2}}$ & $\begin{array}{l}\text { Fill in correctly all the 4 } \\
\text { situations; }\end{array}$ & $\begin{array}{l}\text { Fill in correctly 3 } \\
\text { situations; }\end{array}$ & $\begin{array}{l}\text { Fill in correctly 1-2 } \\
\text { situations; }\end{array}$ \\
\hline $\mathbf{I}_{\mathbf{3}}$ & $\begin{array}{l}\text { Group characters } \\
\text { correctly according to } \\
\text { their traits for all the 5 } \\
\text { situations; }\end{array}$ & $\begin{array}{l}\text { Group characters correctly } \\
\text { according to their traits for } \\
\text { 4 situations; }\end{array}$ & $\begin{array}{l}\text { Group characters correctly } \\
\text { according to their traits for } \\
\text { 2-3 situations; }\end{array}$ \\
\hline $\mathbf{I}_{\mathbf{4}}$ & $\begin{array}{l}\text { Fill in correctly all the 4 } \\
\text { situations; }\end{array}$ & $\begin{array}{l}\text { Fill in correctly 3 } \\
\text { situations; }\end{array}$ & $\begin{array}{l}\text { Fill in correctly 1-2 } \\
\text { situations; }\end{array}$ \\
\hline $\mathbf{I}_{\mathbf{5}}$ & $\begin{array}{l}\text { Make a suggestive } \\
\text { drawing to illustrate the } \\
\text { proverb; }\end{array}$ & - & - \\
\hline
\end{tabular}

By analysing the results from the final evaluation, it was found that out of 90 students, 60 students (67\%) obtained the mark Very Well and 30 students (33\%) failed to meet the tasks' correctness requirements, getting the mark of Well. These students too are aware of the moral traits of a person, but they made some confusion between terms (Figure 1).

Fig. 1. Comparative histogram of the results to initial and final assessment

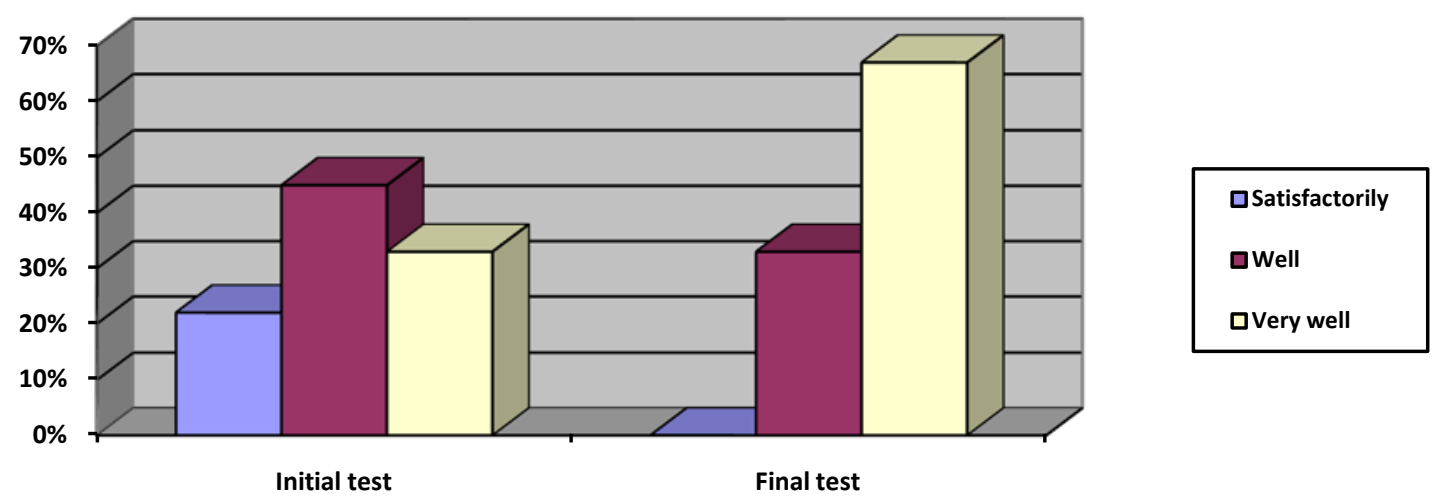

\section{CONCLUSIONS}

The crisis of moral values of today's society also triggers a family crisis. The educational role of the family, challenged by so many problems and itself in search of a vocation that would ensure its future place in society, is becoming increasingly devoid of substance.

(c) The International Journal of Indian Psychology, ISSN 2348-5396 (e)| ISSN: 2349-3429 (p) | 168 


\section{Building Socio-Moral Behaviour in Romanian Middle-School Education}

In this situation, the instructive-educational process provides the child, besides with intellectual education, also with an age-appropriate physical and aesthetic education and moral orientation in the system of his relations with the surrounding world that may lead to the crystallization of moral qualities and the accumulation of the most elementary behaviour skills.

Appropriating various moral concepts, students began to issue rightful moral judgments that will be used in their own behaviour. Designing and experimenting this module of activities was achieved by taking into account the curriculum and psychological profile of the students' age. By the teaching strategies applied it was found that certain activities with moral content used in the educational process require a real understanding of the level of behaviour development and moral conduct.

The final evaluation results supported us in generating the following conclusions: - the student should perceive the positive sense of moral conduct when the moral situation provides us with another meaning; - the students' responsiveness to and interest in the beauty of the various aspects of moral behaviour that, once triggered, must be stimulated and maintained; - the teacher should use as much variety as possible to encourage students to perceive the transmitted message and then to internalize it; - the teacher should be a true behaviour role model for students, and there should be created a real bond between teacher and students.

\section{Acknowledgments}

The author appreciates all those who participated in the study and helped to facilitate the research process.

\section{Conflict of Interests}

The author declared no conflict of interests.

\section{REFERENCE}

Allport, Gordon W, (1981), Structure and personality development, Didactic and Pedagogic, Bucharest;

Bunescu, V, (1998), School and moral values, Didactic and Pedagogic, Bucharest;

Calin Marin C., (2003), Theory and meta educative action, Aramis Publishing, Bucharest;

Cucoș, C, (2006), Pedagogy, Polirom Publishing, Iasi;

Dumitriu, C, (2007), Foundations of Pedagogy. Theory and Methodology, Publisher Alma Mater, Bacau;

Jeder, D, (2006), Levels of morality and moral education, E.D.P.R.A., Bucharest;

Lupu, C \& Savulescu, D, (1998), Teaching mathematics (Didactica matematicii), Manual for Class XI, Paralela 45 Publishing, Pitesti. 


\section{Building Socio-Moral Behaviour in Romanian Middle-School Education}

Lupu, C, (2014), Research on the Individual Development of Children by eliminating stressors, The International Journal of Indian Psychology, IJIP, Volume 2, Issue 1. https://www.academia.edu/11117076/

Lupu, C, (2015), The Negative Impact of the Economic Level on the Poor Students' School Success, The International Journal of Indian Psychology, Volume 3, Issue 1, No.4, Page: 103 to 115. http://oaji.net/articles/2015/1170-1445362774.pdf

Macavei, E, (2001), Pedagogy - Theory of Education, Aramis, Bucharest;

Miroiu, M, (2002), About nature, women and morality, Polirom Publishing, Iasi.

Nicola, I, (2001), Treaty of school pedagogy, Aramis Publishing, Bucharest;

Piaget, J, (1980), The moral judgment of the child, E.D.P., Bucharest;

Sarah Javed, Javed Salma, Arfa Khan, (2016), Effect of Education on Quality of Life and Well Being, The International Journal of Indian Psychology, Volume 3, Issue 3, No. 58, http://www.ijip.in / DIP: 18.01.053 / 20,160,304

How to cite this article: C Lupu (2016), Building Socio-Moral Behaviour in Romanian MiddleSchool Education, International Journal of Indian Psychology, Volume 3, Issue 4, No. 66, ISSN 2348-5396 (e), ISSN: 2349-3429 (p), DIP:18.01.171/20160304, ISBN: 978-1-365-39396-9 